\title{
Custom synthesis of molecular imprinted polymers for
}

\section{biotechnological application. Preparation of a polymer}

\section{selective for tylosin}

\author{
Sergey Piletsky ${ }^{a}$, Elena Piletska ${ }^{a}$, Kal Karim ${ }^{a}$, Graham Foster $^{b}$, Colton \\ Legge $^{b}$, Anthony Turner ${ }^{a}$ \\ a Institute of BioScience and Technology, Cranfield University, Silsoe, Bedfordshire, \\ MK45 4DT, UK \\ b GlaxoSmithKline Research and Development, Gunnels Wood Road, Stevenage, Herts, \\ SG1 2NY, UK
}

\begin{abstract}
A molecularly imprinted polymer (MIP) selective for tylosin was designed and synthesised using a computational method (MIP “dialling”). In re-binding experiments the MIP demonstrated high affinity for tylosin in aqueous solutions and in organic solvents. The synthesised polymer was tested for re-binding with the template and related metabolites such as tylactone, narbomycin and picromycin. The HPLC analysis showed that the computationally designed polymer is specific and capable of separating the template from its structural analogues. The MIP was capable of recovering tylosin from
\end{abstract}

*Corresponding author.

Tel: +44 (0)1525 863584, fax: +44 (0)1525 863533, e-mail: $\underline{\text { S.Piletsky@cranfield.ac.uk }}$ 
broth samples. The polymer capacity for tylosin was estimated as $6.4 \mathrm{mg} / \mathrm{g}$ for MIP, which was suitable for practical application and tylosin recovery from broth samples. Among the advantages of this was the possibility to adsorb tylosin from a complex media with easy removal of oils and other impurities which are present in significant quantities, which can create problems for its chromatographic purification procedure. The MIP "dialling" procedure can have a general significance for the fast preparation of specific adsorbents for biotechnological applications.

Keywords: Tylosin; Computational design; Molecularly imprinted polymer

\section{Introduction}

For the past three decades MIP technology has been developed as a method for the preparation of synthetic receptors by polymerisation of a self-assembled complex, formed by functional monomers and template [1]. Traditionally the choice of polymer composition is based on information available from the literature about the behaviour of similar systems, individual experience of chemists or extensive experimental trials. Although many polymers perform effectively in separation and sensing [2-5], some practical applications have the need for a fast procedure, MIP "dialling", when a polymer has to be designed and tested within a short period of time (2-4 weeks) to address a specific separation problem. "Dialling" obviously requires the development of a generic protocol for MIP design and testing. The first attempt to develop such a protocol was made using a combinatorial screening approach [6]. The method describes the development of a monomer library, synthesis of MIPs using these monomers and their 
testing in re-binding experiments. As a result it was possible to select monomers from the library, which produced polymers with the highest affinity for the template. Although the method showed its usefulness for the screening of small sets of the polymers it has limited applicability for the testing of large libraries of polymers containing two or more monomers. The number of polymers which can be produced using a combination of two monomers is equal to: $\mathrm{A}=\left(\mathrm{n}^{2}+\mathrm{n}\right) / 2$ where $\mathrm{A}$ is the number of polymers and $\mathrm{n}$ is the number of monomers in the library. If a library contains 100 monomers, more than 5 thousands polymers will have to be synthesised and tested, which is an enormous task. Although automation of the process using robots could resolve this problem partially [7], in practice the synthesis and screening of large libraries of polymers remains difficult for using in routine applications.

Recently we developed a generic protocol for MIP design using a computational approach and molecular modelling software [8-10]. The idea is to simulate a complex formation between the monomers and template in a monomer mixture. A virtual library of the most commonly used functional monomers is designed and screened for their interaction with the template. This selection covers practically all variety of commercially available monomers capable to interact with a template through electrostatic, hydrophobic Van-der-Waals forces and dipole-dipole interactions (Figure 1).

Simulated annealing is used to analyse the organisation of the monomers around the template molecule. At the end of the program, the number and the position of the functional monomers are examined giving information about the optimum MIP composition. The results on the development of MIPs for atrazine, aflatoxin $\mathrm{B}_{1}$, microcystin-LR, creatinine and small-molecular-weight drugs have demonstrated the 
excellent performance of the computational MIPs in separation and sensing. The computational method became a routine tool for design of imprinted polymers in our laboratory and is now validated for use by other groups.

One of the important questions, which should be answered before it is recommended for broad application, is how fast can the molecular modelling be done. This paper describes the first attempt to use a MIP "dialling" protocol for fast-track synthesis of polymeric adsorbents specific for tylosin and use of this adsorbent for tylosin recovery and from broth samples and its purification from other related macrolides.

Tylosin is a 16-membered macrolide antibiotic produced by fermentation of Streptomyces fradiae which is used in veterinary practice as a therapeutic substance in the treatment of Mycoplasmas, Haemophilus influenzae, Chlamidia and Rickettsia infections in poultry and in a livestock. Also, the group of macrolide antibiotics constitutes an important alternative for patients exhibiting penicillin sensitivity and allergy [11].

During fermentation several related metabolites can be formed among which the main interfering compound is tylactone (Tl) (the skeleton of tylosine), narbomycin ( $\mathrm{Nm})$ and picromycin (Pm) (Figure 2). Traditional methods for purification and analysis of macrolides include reverse-phase HPLC on a $\mathrm{C}_{18}$ or polymeric stationary phase [12]. As it was reported, this method has disadvantages such as column dependence towards impurities, long analysis time and high price of polymeric adsorbent. A strong need exists for the rapid isolation of macrolides structurally related to tylosin (Ts) from broth extracts based on solid-phase extraction (SPE) or a chromatographic stationary phase for biotechnological manufacturing of this antibiotic. 


\section{Materials and Methods}

\subsection{Reagents}

Tylosin, tylactone, narbomycin and picromycin were supplied by Biotransformations/Natural Product Chemistry, GlaxoSmithKline R\&D, UK. Ethylene glycol dimethacrylate (EGDMA), itaconic acid (IA), N,N'-methylenebisacrylamide (BAA), acrylamide (AA), methacrylic acid (MA), 1,1'-azobis(cyclohexanecarbonitrile), dichlormethane, ethyl acetate, trifluoroacetic acid and triethylamine were purchased from Aldrich (UK). Dimethylformamide (DMF) was obtained from BDH (UK). All chemicals were analytical or HPLC grade and were used without further purification.

\subsection{Molecular modelling}

The workstation used to simulate monomer-template interactions was a Silicon Graphics Octane running the IRIX 6.4 operating system. The workstation was configured with two $195 \mathrm{MHz}$ reduced instruction set processors, $712 \mathrm{MB}$ memory and a $12 \mathrm{~GB}$ fixed drive. This system was used to execute the software packages SYBYL 6.6 (Tripos Inc., St. Louis, Missouri, USA). The molecular model of tylosin (template) and a virtual library of the 20 commonly used monomers (Figure 2) were created, charges for each atom were calculated and the structure of the template was refined for dielectric constant equal 38 (DMF) using molecular mechanics. The LEAPFROG algorithm was used to screen the library of functional monomers on their possible interactions with the template. 30,000 iterations were completed in approximately 2 hours and results from 
each run were examined by ranking the empirical binding score. In order to estimate the polymer composition and monomer ratio the top three monomers giving the highest binding score and thus capable of forming the strongest complexes with the template molecule were selected for the Simulated Annealing process. The space around the template was saturated with multiple copies of the selected monomers. Annealing conditions were fixed as $1000 \mathrm{~K}-300 \mathrm{~K}$ sweeping in 100,000 consecutive steps. Equilibrium length was determined as 1000 ps. Energy minimisation was performed to $0.01 \mathrm{kcal} \mathrm{mol}^{-1}$ convergence for each iteration. At the end of the program, the number and the position of the functional monomers were examined. The monomers participating in the complex with the template were chosen for the preparation of the molecularly imprinted polymer.

\subsection{Preparation of molecularly imprinted polymers}

The molecularly imprinted polymer (MIP) and non-imprinted (Blank) polymer were synthesised using the ratio obtained by the simulated annealing. The "traditional" MIP was synthesised using methacrylic acid as a monomer (10:1 molar ratio of monomer towards the template). The composition of polymers is presented in Table 1 . The amount of cross-linker (EGDMA) was calculated as $80 \%(\mathrm{w} / \mathrm{w})$ of the functional monomer and template. The polymers were prepared using DMF, which was chosen as a porogen due to the poor solubility of the template in more hydrophobic solvents, such as chloroform and toluene. $1 \%$ of $1,1^{\prime}$-azobis(cyclohexanecarbonitrile) was used to initiate the polymerisation. The corresponding blank polymer was prepared in the same way but in 
the absence of the template. The reaction mixture was purged with nitrogen and then left to polymerise overnight at $80{ }^{\circ} \mathrm{C}$. The bulk polymers were ground in methanol with an electrical mortar SL2 (Silverson, UK) and mechanically wet-sieved through 106 and 38 $\mu \mathrm{m}$ sieves (Endecotts, UK). The template was removed using Soxhlet extraction with methanol (12 hours) followed by washing in an HPLC column with methanol and 5 min cycles of $50 \mathrm{mM} \mathrm{NaOH}$ in $90 \%$ methanol and $50 \mathrm{mM} \mathrm{NaOH}$ in water $(9 \mathrm{ml} / \mathrm{min}, 30$ cycles). The polymer particles with a size range of 38-106 $\mu \mathrm{m}$ were collected, dried under vacuum and used for solid-phase extraction experiments. The particles with size less than $38 \mu \mathrm{m}$ were fractionated by sedimentation in acetonitrile and packed in $250 \mathrm{x}$ 4.7 mm columns and used for HPLC analysis.

\subsection{Solid-phase extraction (SPE)}

SPE was performed with $5 \mathrm{ml}$ cartridges packed with $500 \mathrm{mg}$ of MIP and Blank polymer in a VisiPrep 12-vial vacuum manifold (Supelco, UK) connected to a vacuum pump (KNF Laboport, Neuberger, Germany). $0.5 \mathrm{ml}$ of tylosin solutions $(0.1 \mathrm{mg} / \mathrm{ml})$ in water, 50:50 methanol/broth, dichloromethane and ethyl acetate were loaded onto the cartridges followed by a methanol wash. The samples of fermented broth, spiked with tylosin were also used in SPE in order to explore the possibilities of the practical applications of the designed MIP. To optimise the elution conditions, gradients of different concentrations of ammonia hydroxide from $0.125 \mathrm{M}$ to $2 \mathrm{M}$ in methanol were prepared. All eluted samples were analysed by HPLC using a reverse-phase $\mathrm{C}_{18}$ column $(150 \times 4.6 \mathrm{~mm})$ with a gradient of acetonitrile in water $(0-90 \%)$ containing $0.5 \%$ TFA. The flow rate was $1 \mathrm{ml} / \mathrm{min}$. Tylosin was detected spectrophotometrically at $280 \mathrm{~nm}$. 


\subsection{HPLC analysis}

For the analysis of the MIP recognition properties $1 \mathrm{~g}$ of polymer (particle size $<$ $38 \mu \mathrm{m})$ was suspended in methanol and packed into an HPLC column $(100 \times 4.6 \mathrm{~mm})$ under reduced pressure. The evaluation experiments were carried out using an HPLC system, which included a ConstaMetric-3200 solvent delivery system (LDC Analytical, UK), Perkin-Elmer ISS-100 automatic injection system and a Waters Lambda-Max Model 481 LC Detector (UK). The separation was performed using 3\% acetic acid in chloroform at a flow rate $2 \mathrm{ml} / \mathrm{min}$. Peaks were monitored optically at $280 \mathrm{~nm}$. All reported chromatographic data represent the results of at least 3 concordant experiments. The STD in the experiments was below 5\%. Capacity factors $\left(\mathrm{k}^{\prime}\right)$ were determined from $\mathrm{k}^{\prime}=\left(\mathrm{t}-\mathrm{t}_{\mathrm{o}}\right) / \mathrm{t}_{\mathrm{o}}$, where $\mathrm{t}$ is the retention time of a given species and $\mathrm{t}_{\mathrm{o}}$ is the retention time of the void marker (acetone). Effective separation factors $(\alpha)$ were calculated from the relationship $\alpha=\mathrm{k}_{\mathrm{t}}^{\prime} / \mathrm{k}_{\mathrm{a}}^{\prime}$, where $\mathrm{k}_{\mathrm{t}}^{\prime}$ and $\mathrm{k}_{\mathrm{a}}^{\prime}$ are the capacity factors of tylosin and related macrolides respectively.

\section{Results and discussion}

The necessity to use computational approach for the design of MIP specific for tylosin originated from the fact that "traditional", methacrylic acid based imprinted polymer had a low affinity for the template and did not perform well in separation and purification of this compound (see Figure 5b). It has been anticipated since the relatively high polarity of tylosin necessitated the use of polar DMF as a solvent in polymer 
preparation, which reduces the strength of hydrogen bonds important for template recognition by a polymer. Significantly better results were expected from a "cocktail" polymerisation, when a combination of monomers with different functionalities is used for the polymer preparation [13]. The rational selection of a monomeric "cocktail" for tylosin recognition in this study was performed by using the computational "dialling" procedure $[9,10]$.

\subsection{MIP “dialling” protocol}

The Table 2 shows the key stages used in the MIP design and preparation, constituting the "dialling" protocol.

Obviously an analysis of the MIP performance by HPLC or SPE will contribute additionally to the time spent on the project. Normally this evaluation takes 5-7 days.

\subsection{Polymer design}

The screening of the virtual library of monomers against tylosin resulted in the selection of three monomers with the highest binding energy: itaconic acid $(-27.70 \mathrm{kcal}$ $\left.\mathrm{mol}^{-1}\right), \mathrm{N}, \mathrm{N}^{\prime}$-methylenebisacrylamide $\left(-27.98 \mathrm{kcal} \mathrm{mol}^{-1}\right)$ and acrylamide $(-28.50 \mathrm{kcal}$ $\mathrm{mol}^{-1}$ ) which were used in the subsequent simulated annealing step. This step simulates the pre-arrangement of the functional monomers with the template as it exists in the monomer mixture prior to polymerisation. The practical significance of this step lies in the possibility to identify the best combination of functional monomers by selecting those, which contribute to the interaction with the template whilst avoiding a non- 
productive competition between them. Figure 3 shows the structure of the complex formed by the monomers and tylosin. In accordance with the modelling results 3 molecules of itaconic acid and 2 acrylamide interact with 1 molecule of tylosin (first shell). Additionally 3 itaconic acids, $3 \mathrm{~N}, \mathrm{~N}^{\prime}$-methylenebisacrylamide and 1 acrylamide interact with the first shell of monomers thus stabilising the complex (second shell). Accordingly the MIP was synthesised using a template monomer ratio: tylosin (1): itaconic acid (6): N,N'-methylenebisacrylamide (3) : acrylamide (3) (Table 1). The Blank polymer was synthesised using the same composition but in the absence of the template. Both polymers were ground, washed and packed in SPE cartridges and HPLC columns as described in the Materials and Methods section. In total the design and preparation of polymer samples took 14 days.

\subsection{SPE analysis}

SPE cartridges packed with $500 \mathrm{mg}$ of polymer were tested on their ability to bind the template. It was found that under neutral conditions the MIP and Blank polymers adsorb tylosin completely (1- $200 \mu \mathrm{g} / \mathrm{ml}$ concentration) from water samples as well as from organic extracts (ethyl acetate, 50\% methanol, chloroform and dichloromethane). It was possible to use methanol to wash out the interfering compounds present in fermentation broth samples in high quantities such as lipids and tylactone (Figure 4). Elution was performed under basic conditions. $95-100 \%$ tylosin recovery was achieved using methanol with $0.5 \mathrm{M}$ ammonium hydroxide. Related macrolides, narbomycin and picromycin, similar to tylosin, were also adsorbed completely from aqueous and organic 
solutions by both polymers. Tylactone, an interfering compound present in the broth extract, adsorbed from water but passed through the polymers without retention in organic solvents. Elution of tylosin could also be carried out in strong acidic conditions. As expected the elution conditions differed for the MIP and Blank polymer. Thus it was possible to achieve complete recovery of tylosin and narbomycin from the Blank polymer using $3 \mathrm{mM}$ trifluoroacetic acid (TFA) but the MIP needed a higher $6 \mathrm{mM}$ TFA concentration. Acetic acid which was dissolved in ethyl acetate (concentration range 30 $\mathrm{mM}-500 \mathrm{mM}$ ), failed to remove analytes from the polymer, which reflects the strength of interactions formed between the monomers and template.

Analysis of the MIP and Blank polymers capacity for tylosin has showed that the imprinted polymer adsorbed $30-50 \%$ more tylosin (depending on conditions) than the Blank polymer. The polymer capacity for tylosin dissolved in buffer was estimated as 6.4 $\mathrm{mg} / \mathrm{g}$ (MIP) and $4.4 \mathrm{mg} / \mathrm{g}$ (Blank). These values are acceptable for practical application of both MIP and Blank polymers as a stationary phase in SPE and preparative chromatography.

Experiments with tylosin adsorption from a diluted solution $(1 \mu \mathrm{g} / \mathrm{ml})$ have confirmed that it is possible to use both MIP and Blank polymers for sample preconcentration (the $95 \%$ recovery of tylosin was achieved with a concentration factor of $100)$.

The MIP performed better in recovery of tylosin from broth samples than most traditional SPE materials. An intriguing possibility is to use for the extraction both, aqueous and organic solvents. 


\subsection{HPLC experiments}

In the extraction experiments described above the MIP has not shown an individual specificity for tylosin. Nevertheless under more gentle chromatographic conditions it was possible to separate the mixture of tylosin, picromycin, narbomycin and tylactone using the MIP (eluent: 3\% acetic acid in chloroform) but not the Blank polymer and MA-based imprinted polymer (Figure 5). Even better recognition was achieved with the MIP with $2 \%$ of acetic acid (Table 3), although the peaks were broad due to high level of heterogeneity of the binding sites present in MIPs [14] and also due to an irregular size and shape of the ground particles used for column preparation. Although it was not the goal of the present study, it is important to note that potentially it is possible to improve the performance of the column by using smaller size particles and by applying gradient elution.

\section{Conclusions}

A selective polymer for tylosin was designed, prepared and tested in a short time (21 days) using a computational MIP "dialling" approach. To perform the traditional screening of 20 monomers, their possible combinations and optimisation of MIP composition, judging from our experience, would require at least ten times longer. The computationally designed MIP possessed the required affinity and specificity, which were much higher than traditional and blank polymers. It was possible to recover tylosin quantitatively from crude broth extracts. Due to the low price and ability to work in aqueous and organic solutions the MIP could be recommended as a new SPE resin for 
sample pre-treatment of macrolides. As a tylosin-selective polymer the MIP can also be used for preparative separation of tylosin from its analogues.

Acknowledgement. SP would like to acknowledge with gratitude receiving Royal Society-Wolfson Research Merit Award. 


\section{References}

[1] G. Wulff and A. Sarhan, Angew. Chem. Int. Ed. Engl. 11 (1972) 341.

[2] S. Hjerten, J.-L. Liao, K. Nakazato, Y. Wang, G. Zamaratskaia, H.-X. Zhang, Chromatographia 44 (1996) 227.

[3] A.L. Jenkins, O.M. Uy, G.M. Murray, Anal. Chem. 71 (1999) 373.

[4] S.A. Piletsky, T.L. Panasyuk, E.V. Piletskaya, I.A. Nicholls, M. Ulbricht, J. Membr. Sci. 157 (1999) 263.

[5] G. Vlatakis, L.I. Andersson, R. Müller, K. Mosbach, Nature 361 (1993) 645.

[6] F. Lanza, B. Sellergren, Anal. Chem. 71 (1999) 2092.

[7] T. Takeuchi, D. Fukuma, J. Matsui, Anal. Chem., 71 (1999) 285.

[8] S.A. Piletsky, R.M. Day, B. Chen, S. Subrahmanyam, O. Piletska, A.P.F. Turner, PCT/GB01/00324 (2000).

[9] S.A. Piletsky, K. Karim, E.V. Piletska, C.J. Day, K.W. Freebairn, C.H. Legge, A.P.F. Turner,'Analyst 126 (2001) 1826.

[10] S. Subrahmanyam, S.A. Piletsky, E.V. Piletska, B. Chen, K. Karim, A.P.F. Turner, Biosensors \& Bioelectronics 16 (2001) 631.

[11] I. Kanfer, M.F. Skinner, R.B. Walker, J. Chromatogr. A 812 (1998) 255.

[12] Y.V. Heyden, J. Saevels, E. Roets, J. Hoogmartens, D. Decolin, M.G. Quaglia, W. Van den Bossche, R. Leemans, O. Smeets, F. Van de Vaart, B. Mason, G.C. Taylor, W. Underberg, A. Bult, P. Chiap, J. Crommen, J. De Beer, S. H. Hansen, D.L. Massart, J. Chromatogr. A 830 (1999) 3.

[13] O. Ramström, L.I. Andersson, K. Mosbach, J. Org. Chem. 58 (1993) 7562. 
[14] B. Sellergren and K.J. Shea, J. Chromatogr. A 690 (1995) 29. 


\section{Figures legends}

Figure 1. Virtual library of functional monomers.

Figure 2. Structures of tylosin and related macrolides used in this study.

Figure 3. A computationally derived structure of the complex formed around tylosin by the monomers: itaconic acid (green), N,N'-methylenebisacrylamide (red) and acrylamide (brown).

Figure 4. Typical chromatograms of a broth sample purification by SPE using a MIP specific for tylosin: a) fermentation broth sample before extraction, b) elution of tylosin using $0.5 \mathrm{M} \mathrm{NH}_{4} \mathrm{OH}$ in methanol. Chromatographic conditions: stationary phase: reverse-phase C18 column 100x4.6 mm I.D.; mobile phase: gradient of acetonitrile in water $(0-90 \%)$ containing $0.5 \%$ TFA; flow rate: $1 \mathrm{ml} / \mathrm{min}$; column temperature: $25^{\circ} \mathrm{C}$, UV detection at $280 \mathrm{~nm}$.

Figure 5. HPLC separation of tylosin and its analogues via MIP and Blank polymers: a) computational polymers, b) “traditional” MIP polymer based on MA as a monomer. Chromatographic conditions: column 100x4.6 mm I.D.; mobile phase: 3\% acetic acid-chloroform, flow rate: $2 \mathrm{ml} / \mathrm{min}$, amount injected- $20 \mu \mathrm{g}$ of each compound; column temperature: $25{ }^{\circ} \mathrm{C}$; UV detection at $280 \mathrm{~nm}$. All injections were made in triplicate and demonstrated STD equal 5\%. 
Table 1. Polymer composition.

\begin{tabular}{|c|c|c|c|c|}
\hline & Components & $\begin{array}{c}\text { Computational } \\
\text { MIP }\end{array}$ & $\begin{array}{c}\text { Computational } \\
\text { Blank }\end{array}$ & $\begin{array}{c}\text { Traditional } \\
\text { MIP }\end{array}$ \\
\hline Template & Tylosin & $\begin{array}{c}1 \mathrm{mmol} \\
(916 \mathrm{mg})\end{array}$ & - & $\begin{array}{c}1 \mathrm{mmol} \\
(916 \mathrm{mg})\end{array}$ \\
\hline \multirow[t]{4}{*}{ Monomers } & Itaconic acid & $\begin{array}{c}6 \mathrm{mmol} \\
(780 \mathrm{mg})\end{array}$ & $\begin{array}{c}6 \mathrm{mmol} \\
(780 \mathrm{mg})\end{array}$ & - \\
\hline & $\begin{array}{l}\text { N,N'-methelene- } \\
\text { bisacrylamide }\end{array}$ & $\begin{array}{c}3 \mathrm{mmol} \\
(423 \mathrm{mg})\end{array}$ & $\begin{array}{c}3 \mathrm{mmol} \\
(423 \mathrm{mg})\end{array}$ & - \\
\hline & Acrylamide & $\begin{array}{c}3 \mathrm{mmol} \\
(213 \mathrm{mg})\end{array}$ & $\begin{array}{c}3 \mathrm{mmol} \\
(213 \mathrm{mg})\end{array}$ & - \\
\hline & Methacrylic acid & - & - & $\begin{array}{l}10 \mathrm{mmol} \\
(860 \mathrm{mg})\end{array}$ \\
\hline $\begin{array}{l}\text { Cross- } \\
\text { linker }\end{array}$ & EGDMA & $\begin{array}{l}47 \mathrm{mmol} \\
(9328 \mathrm{mg})\end{array}$ & $\begin{array}{c}47 \mathrm{mmol} \\
(9328 \mathrm{mg})\end{array}$ & $\begin{array}{c}36 \mathrm{mmol} \\
(7104 \mathrm{mg})\end{array}$ \\
\hline Solvent & $\overline{\mathrm{DMF}}$ & $\begin{array}{c}159 \mathrm{mmol} \\
(11660 \mathrm{mg})\end{array}$ & $\begin{array}{c}159 \mathrm{mmol} \\
(11660 \mathrm{mg})\end{array}$ & $\begin{array}{l}121 \mathrm{mmol} \\
(8880 \mathrm{mg})\end{array}$ \\
\hline Initiator & $\begin{array}{l}\text { 1,1'-Azobis- } \\
\text { (cyclohexane } \\
\text { carbonitrile) }\end{array}$ & $\begin{array}{l}0.9 \mathrm{mmol} \\
(233 \mathrm{mg})\end{array}$ & $\begin{array}{l}0.9 \mathrm{mmol} \\
(233 \mathrm{mg})\end{array}$ & $\begin{array}{l}0.7 \mathrm{mmol} \\
(177 \mathrm{mg})\end{array}$ \\
\hline
\end{tabular}


Table 2. Timetable of MIP design and preparation.

Procedure

Time (days)

Development of molecular model of the template

1

and screening of the virtual library of monomers

Simulated annealing. Analysis of the complex 7

and identification of the template-monomers ratio

\begin{tabular}{ll}
\hline Synthesis of the polymer, grinding and sieving & 2 \\
\hline Soxhlet extraction with methanol & 1 \\
\hline Washing of the polymer on-line & 2 \\
\hline Drying of the polymer and packing of SPE \\
cartridges and/or HPLC column \\
\hline$\quad$ Total time & $\mathbf{1 4}$ \\
\hline
\end{tabular}


Table 3. Separation of tylosin and analogues on MIP and Blank polymer using $2 \%$ acetic acid in chloroform.

\begin{tabular}{ccccc}
\hline Compounds & MIP (k') & Blank (k') & MIP $(\alpha)$ & Blank $(\alpha)$ \\
\hline Tylosin & 8.8 & 2.87 & 1 & 1 \\
\hline Picromycin & 4.35 & 2.05 & 2.03 & 1.4 \\
\hline Narbomycin & 3.8 & 1.83 & 2.31 & 1.83 \\
\hline Tylactone & 1.05 & 1.05 & 8.4 & 2.73 \\
\hline
\end{tabular}




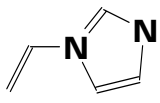

F1 1-VINYLIMIDAZOLE

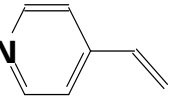

F5 4-VINYLPYRIDINE

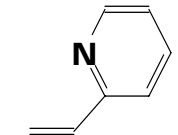

F2 2-VINYLPYRIDINE<smiles>C=CC=O</smiles>

F6 ACROLEIN

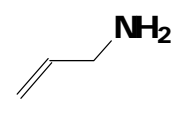

F10 ALLYAMINE

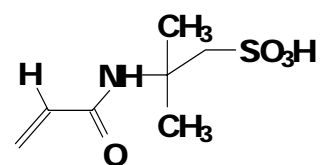

F3 ACRYLAMIDO-2-METHYL-1PROPANESULFONIC ACID (AMPSA)

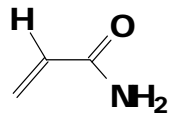

F7 ACRYLAMIDE<smiles>C=C(C)C(=O)OCCO</smiles>

F4 2-HYDROXYETHYL METHACRYLATE

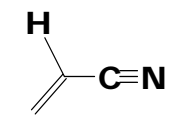

F9 ACRYLONITRILE
$\mathrm{NH}_{2}$

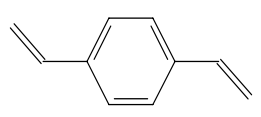

F11 p-DIVINYLBENZENE<smiles>C=C(C)C(=O)OCCOC(=O)C(=C)C</smiles>

F12 ETHYLENE GLYCOL DIMETHACRYLATE (EGDMA)<smiles>CCOC(O)CCc1c[nH]cn1</smiles>

F13 UROCANIC ACID ETHYL ESTER<smiles>C=C(CC(=O)O)C(=O)O</smiles>

F14 ITACONIC ACID<smiles>C=Cc1cccc(C=C)c1</smiles>

F15 m-DIVINYLBENZENE<smiles>C=C(C)C(=O)O</smiles>

F8 ACRYLIC ACID<smiles>C=C(C)C(=O)O</smiles>

F17 METHACRYLIC ACID

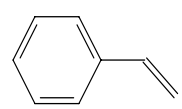

F18 STYRENE

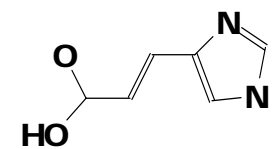

F19 UROCANIC ACID<smiles>C=C(C)C(=O)OCCN(CC)CC</smiles>

F20 N,N-DIETHYLAMINO ETHYL METHACRYLATE (DEAEM)<smiles>C=C(C(=O)O)C(F)(F)F</smiles>

F21 2-(TRIFLUOROMETHYL)ACRYLIC ACID

Figure 1. Piletsky et al. 
<smiles>CC[C@H](OC(=O)C(C)C(=O)[C@@H](C)[C@@H](O[C@@H]1O[C@H](C)C[C@H](N(C)C)[C@H]1O)[C@@H](C)C[C@@H](C)C(=O)/C=C/[C@@H](C)C(C)C)C(=O)O</smiles>

Narbomycin

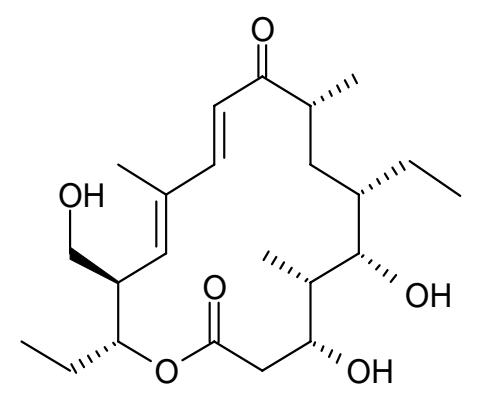

Tylactone

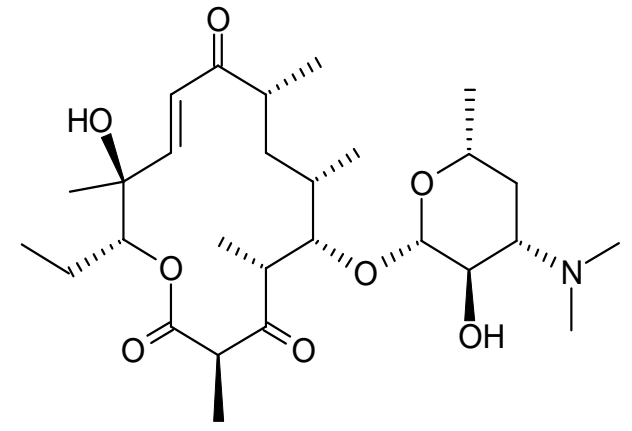

Picromycin

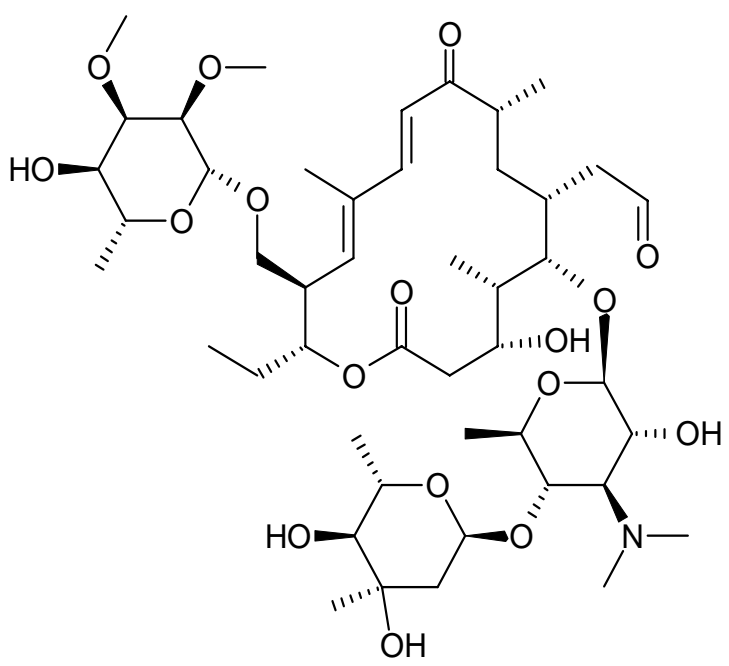

Tylosin

Figure 2. Piletsky et al. 


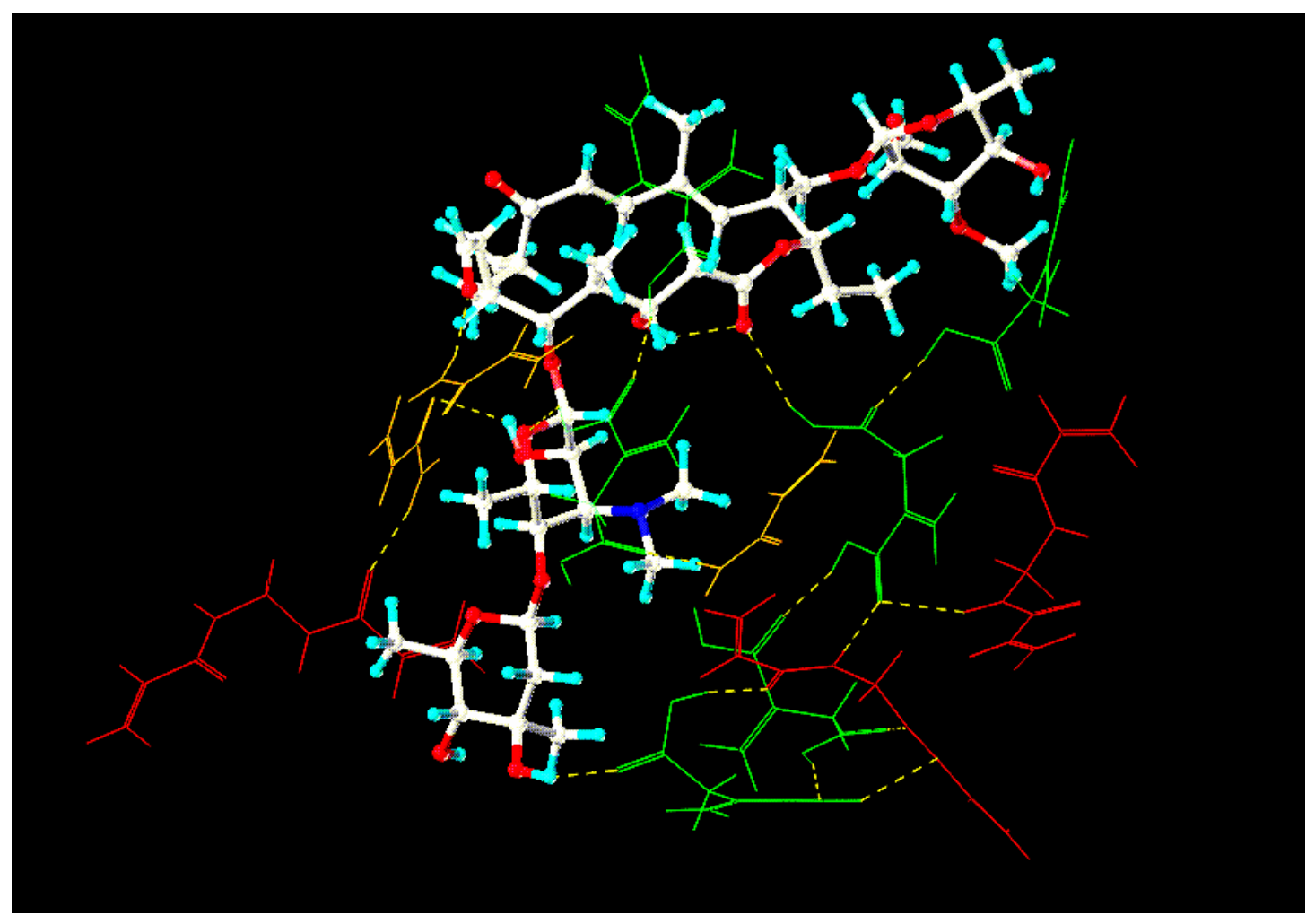

Figure 3. Piletsky et al. 

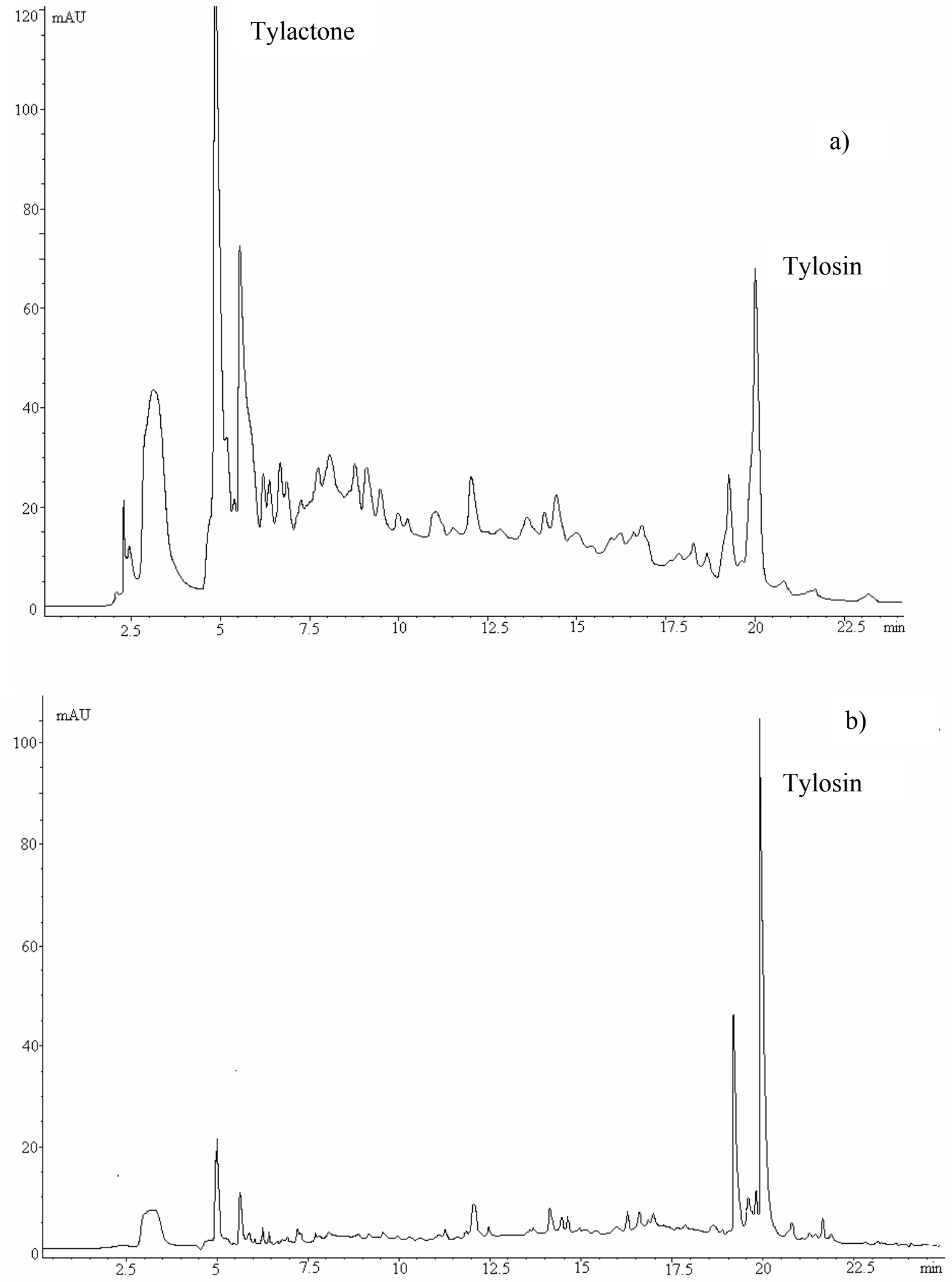

Figure 4. Piletsky et al. 
a)

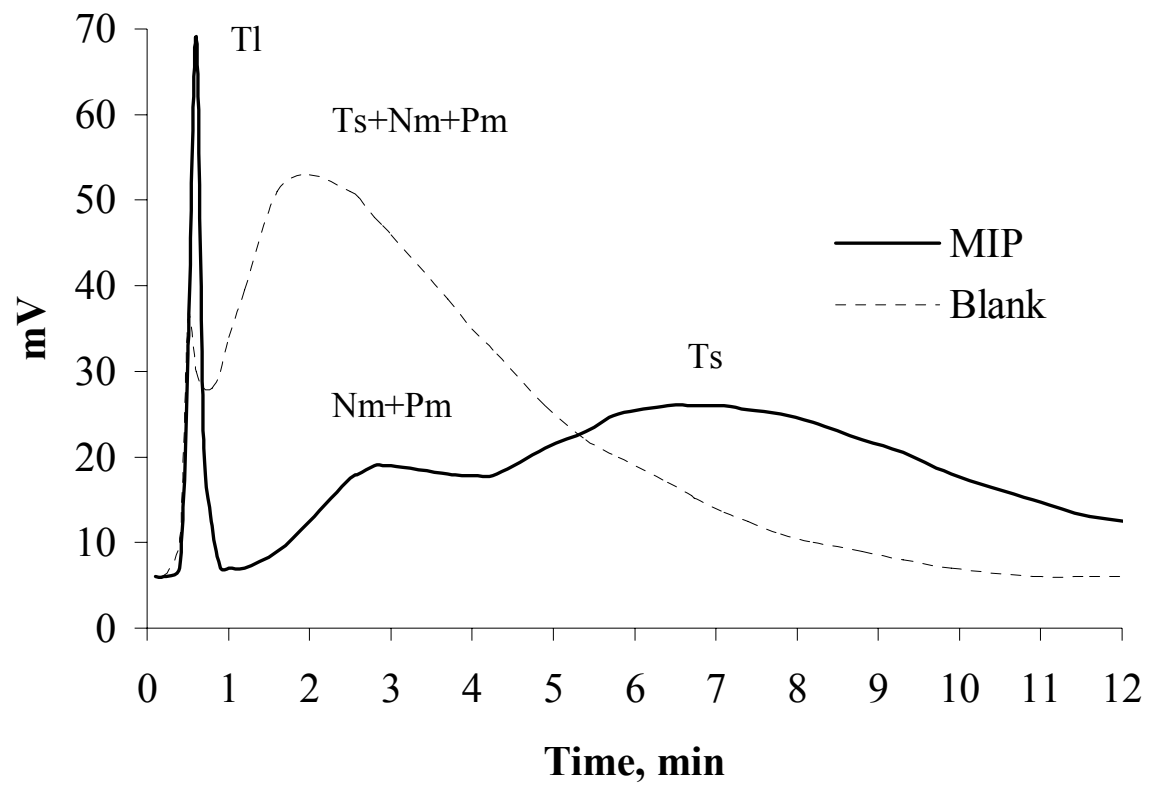

b)

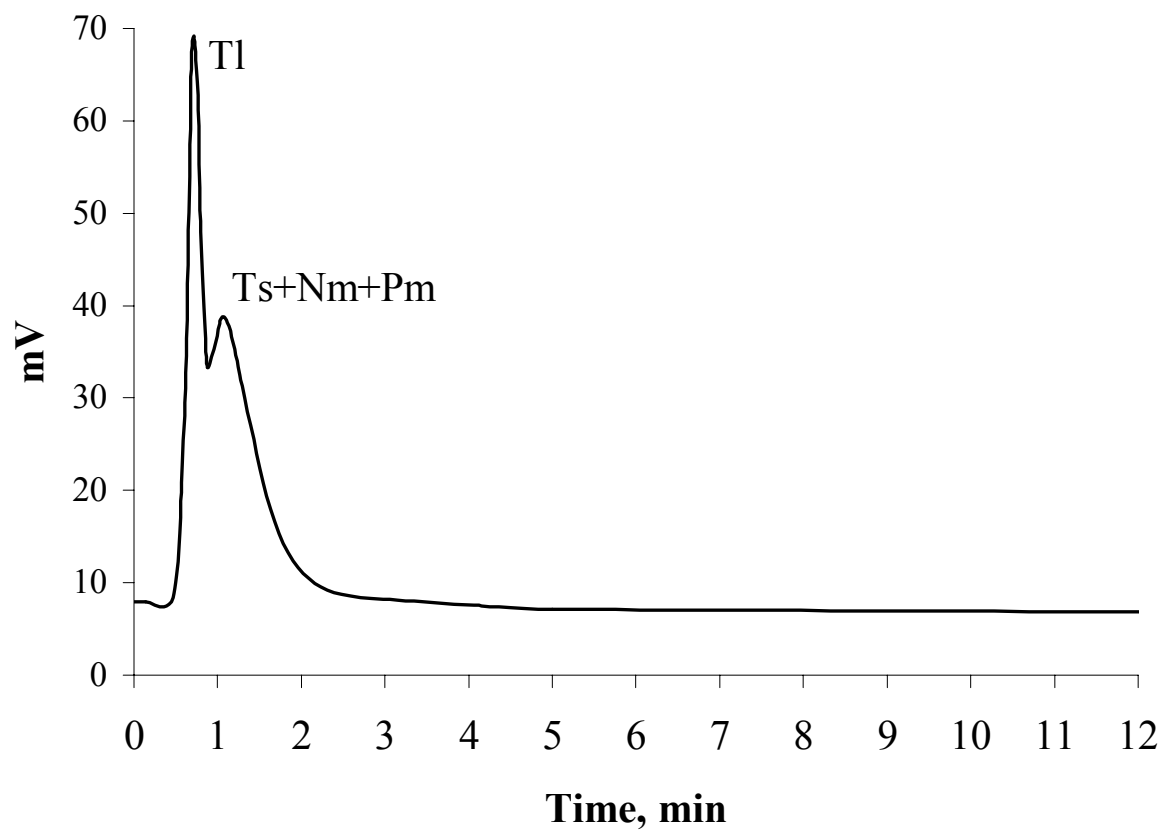

Figure 5. Piletsky et al. 
